which has become too small to accommodate a prothesis. For the rest the article is taken up mainly with a description of all the numerous disheartening difficulties which beset the path of the surgeon who has to deal with a contracted or distorted socket, more especially of the type resulting from war injuries. Special reference is also made to the method of Verhoeff, adopted by the author, of preventing renewed cicatricial contraction after extirpation of cicatricial tissue in the operation for contracted socket. Verhoeff employs a large dermo-epidermic graft wrapped round a glass ball, placing the epidermis next the ball and the raw surface next the dissected orbital tissue. He then makes use of the resistance of the ball to exert pressure of the graft against the orbital tissue.

With regard to the method of fornicoplasty which Majewski himself describes and illustrates very clearly; this consists in making an incision from one angle of the lower eyelid conjunctiva to the other at about 8 to $10 \mathrm{~mm}$. from the margin. After dissecting the conjunctiva the knife is plunged deeply into the subjacent tissue, which is incised in its whole length almost to the lower orbital margin. No tissue is excised. By means of strong sutures the conjunctiva is then drawn down into the wound after the manner of Snellen's suture for ectropion and the sutures tied over a roll of cotton on the skin surface. The result is a new cul-de-sac which is lined by the conjunctiva on its anterior face, the posterior face being necessarily a raw surface. The number of sutures required depends upon whether the fornix is wholly or only partially obliterated.

Mutatis mutandis the author operates in the same manner where the upper fornix is concerned. Sometimes a double fornicoplasty is called for.

Majewski's article is well written and will repay perusal in the original.

ERNEST THOMSON.

\title{
BOOK NOTICE
}

Chirurgie de l'Oeil et de ses Annexes. Par F. TERrien, Professeur agrégé à la Faculté de Médecine de Paris. Deuxième édition augmentée et entièrement refondue. Paris : Masson et Cie. 1921. 50 francs.

During the nineteen years which have elapsed since the publication of the first edition of this book, many notable advances 
have been made in ocular surgery, and the practice and technique of ophthalmic surgeons have undergone many important modifications. A comparison of the two editions gives a vivid impression of the nature and extent of these changes, while but little consideration of them is necessary to appreciate how largely recently-devised methods and operations are the direct outcome of progress in pathology and bacteriology.

The general plan of this edition follows that of its predecessor, but with alterations which add considerably to the comfort of the reader; e.g., the table of contents has been transferred from the end of the book to its rightful position at the beginning, and the index has been made really serviceable. Though smaller in size, the book contains 181 more pages, and much space for letterpress has been gained by reducing the size of the illustrations, without in any way impairing their value. The author's belief that the ideal book on surgery, as on anatomy, should teach as much by illustrations as by the text, is manifest in a very liberal supply of drawings and diagrams ; in many instances each step of an operation is shown by a separate figure. It is, perhaps, well to mention, for students unfamiliar with methods other than those commonly adopted in this country, that when operating, French ophthalmic surgeons stand in front of the patient much more frequently than is the custom here. Another point to bear in mind is that operations are described in relation to the structures involved, not in relation to disease ; e.g., the treatment of glaucoma will be found partly in the chapter on operations on the sclera, and partly in that on operations on the iris. It is true that at the end of the latter chapter there is a brief epitome of procedures for combating increased intraocular tension, classified in two groups; those which (usually) have a temporary effect (Opérations hypotonisantes), and those which are more lasting in their results (Opérations fistulisantes).

The preliminary chapter of 22 pages on pre-operative technique has been greatly modified and extended; in addition to detailed instructions as to asepsis, in its widest sense, it contains a full description of the means of inducing local and regional anaesthesia of superficial and intraorbital structures.

Sterilization of instruments by dry heat is, in the author's view, superior to all other methods, and preference is given to an electrically-heated sterilizer, as maintaining a more uniform temperature than is obtained by gas or spirit flame.

The chapter on the cornea, which follows, contains among the additions to the old volume, recent surgical methods of dealing with ulcers of the cornea, and an instructive section on recent research and experience in transplantation of the cornea.

Operations on the sclera, which in the first edition occupied halfa-dozen pages, now demand a whole chapter extending to nearly $\mathbf{5 0}$ 
pages. A large proportion of this chapter is devoted to sclerectomy with the establishment of a fistulous scar, proposed by Lagrange in 1906 for the treatment of glaucoma, and since that time practised in diverse ways by ophthalmic surgeons generally. Most of the established procedures are described and illustrated, but we think that additional figures showing the application of the punch and trephine respectively would be helpful to the student. The author holds that, at the present time, the operation of selection in chronic glaucoma is fistulization by resection of a fragment of the sclera by knife, scissors, punch or trephine. He gives preference to trephining on the lines devised by Elliot. In acute glaucoma this operative procedure should never be employed.

Cataract is dealt with exhaustively in three chapters, one upon extraction of senile cataract, one upon accidents and complications of the operation, followed by a section on the vision of the aphakic eye, and a third on the operative measures to be adopted in secondary, congenital and complicated cataract. Terrien advises the beginner to give his attention first to these chapters. He regards simple extraction as the more perfect operation, but emphasizes the difficulties, and the greater risk of complications, and indicates the class of cases for which it should be reserved. It should "always be preceded by a corneal suture." (It is an interesting commentary on the ever-changing character of medical knowledge, that in the first edition the author expressed the opinion that suture of the cornea and lavage of the anterior chamber in cataract operations were "useless and dangerous.")

Extraction in the capsule is " the ideal method and is probably the operation of the future," but the liability to complications is so pronounced that, despite Smith's and Barraquer's results, it cannot yet be recommended.

The chapter on enucleation of the eyeball and alternative operations has been much augmented and includes a detailed account of present-day methods of improving ocular prothesis, many of which were evolved as a result of war experience. While recognizing that the best stump for an artificial eye is a natural one (an atrophied eyeball, or the posterior segment of it), the author considers that the risk of sympathetic mischief renders the procedure generally inadvisable. When enucleation is performed he strongly advocates the employment of a graft of costal cartilage or of a pedunculated subcutaneous flap from the temporal region (Lagrange), to each of which the divided recti tendons are attached.

The second part of the book, "Operations on the Adnexa," contains chapters dealing with the surgery of the ocular muscles, the conjunctiva, the lacrimal apparatus and the eyelids, and concludes with a section on lumbar puncture in ocular affections, and disturbances of vision induced by tumours of the hypophysis. It is 
impossible within the limits of this notice to refer to the contents of each chapter; but the student will find therein ample and up-to-date information. Much of it pertains to operative procedures and technique devised or evolved since the first edition appeared, as for example, dacryo-cysto-rhinostomy operations, the accurate localisation and removal of foreign bodies in the eyeball and orbit, and the more modern plastic surgery of the eyelids.

The author, in his preface, writes:- "Faire voir et bien voir, tel était le but que nous avions essayé d'atteindre." In our judgment this aim has been successfully attained. The book is well written, the descriptions of operations are very clear and easy to follow, the choice of illustrations and their execution is admirable. We have read the volume with great pleasure.

The publishers have done their part thoroughly, the text is singularly free from errors, and the printing of the letterpress and of the illustrations is excellent.

J. B. LAWFORD.

\section{CORRESPONDENCE}

\section{SMALL FLAP SCLEROTOMY.}

To the Editor of THE BRITISH JOURNAL OF OphTHALMOLOGY.

SIR,- - I realize that you have already given to this discussion more space than its interest may deserve, but I would ask you kindly to allow me to answer Colonel Herbert mainly on questions of fact.

He accuses me of questioning the existence of drainage through the wound, of which a section was shown in his paper. I did not do so. On the contrary, in my third paragraph, I have admitted the presence of the drainage claimed twice over in five lines. I took exception, and I still take exception, to the confusion of this temporary drainage, with which we are all familiar, with permanent drainage, in defiance of clinical experience and in the absence of anatomical evidence.

He accuses me again of the mistake of confusing the sclero-corneal scar with the secondary conjunctival changes over it. I have never made such a mistake; but inasmuch as the scar is covered by conjunctiva, and inasmuch as the alterations in that membrane may hide the fistula, I can only repeat my statement, that it is not possible to say, from the mere inspection of a scar, that it is not fistulous. Colonel Herbert thinks that much misconception would be avoided if the scars were studied with focal illumination and a + 20 D. lens. I, personally, have always used the more accurate method of employing a corneal microscope for the same purpose. 